\title{
Perception of Postgraduate Students on Customer Service at the School of Graduate Studies, University of Cape Coast
}

\author{
Betty K. Addo-Nkrumah \\ Directorate of Human Resource, University of Cape Coast \\ Email: baddo-nkrumah@ucc.edu.gh
}

\begin{abstract}
The aim of this study was to examine the quality of service provided by the School of Graduate Studies, University of Cape Coast to its students (customers). This study employed a descriptive survey design. A questionnaire designed by the researchers was used to obtain data from 400 postgraduate students (customers), using the stratified sampling technique. Data were presented and analyzed using descriptive statistics which included frequencies, percentages, means and standard deviation. The study found that staff members at the School of Graduate Studies, University of Cape Coast provide quality services to postgraduate students at different dimensions
\end{abstract}

when they seek assistance. It was therefore recommended that the Directorate of Human Resource in collaboration with Training and Development Section of the University of Cape Coast should include aspect of customer care topics in the training programmes for all categories of staff in order to improve professionalism in tangibility dimension of service delivery.

Keywords: Customer expectation, customer service, perception, service quality, quality dimensions, student satisfaction 


\section{Introduction}

In recent years, organisations have placed increasing emphasis on customer service as a means of gaining an edge over their competitors, since it has been realised that the customer is the foundation of business and the reason for existence. It has, therefore, become necessary for the growth and sustenance of a business (Cook, 2008) to treat customers with utmost respect, ensuring their satisfaction through good customer relationships. Good customer service is the life blood of any business. It is all about bringing customers back to the organisation. In the case of the universities, students, alumni, as well as other stakeholders constitute customers. Understanding customer expectations is a prerequisite for delivering superior service as customers compare perceptions with expectations when judging a firm's services (Parasuraman, Zeithaml, \& Malhotra, 2005). Good customer service is not an exception in higher education. Although many higher education institutions run away from the idea that they should be customer focused, Govender, Veerasamy and Noel (2012) argue that service quality in higher education is described as a measurement of how well higher education institutions conform to customers' needs and expectations. Students have been identified as the primary customers in universities (Karami \& Olfati, 2012). Seen in this light, it is imperative that universities continue to build and maintain stronger relationship with their students by providing stronger relationship and educational services. Universities must also be interested in the perception of their students regarding educational services as it relates to their satisfaction (Hanaysha, Abdullah \& Warokka, 2011; Russell, 2005). However, arguments in contemporary literature suggest that management of higher learning institutions, should not only deliver services to meet social expectations to appreciate student perceptions, drawn from their long-term experience within an academic environment (Munteanu et al., 2010). Tutu-Boahene and Mawuli (2014) suggest that little research efforts have been put into 
investigating graduate students' experience in higher education institutions.

The mission of the University of Cape Coast is to provide quality education through the provision of comprehensive, liberal and professional programmes that challenge learners to be creative, innovative and morally responsible citizens. Good customer service should take into consideration the mission of the institution in order to gain a competitive edge over its competitors. As a University, students are the most vital resources; without them the university would not be able to exist and function as an organisation or business. The University of Cape Coast offers a range of programmes and support services to help students. Apart from getting the students on the programmes of their choice, the University provides support services to facilitate knowledge acquisition in addition to its core mandate of teaching and research, such as orientation service, student mentorship, seminars and workshops, chaplaincy service, financial help, guidance and counseling service and security services $\left(50^{\text {th }}\right.$ VC's Annual Report 2018).

The School of Graduate Studies of the University of Cape Coast has a mandate to advice Senate on the University's graduate scholarship policy and recommend the award of scholarships for approval. The vision of the School is to become the hub of an outstanding multidisciplinary context for graduate training and research for advancing the socio-economic development of Ghana. The School of Graduate Studies is to ensure the relevance of graduate programmes for the promotion of economic, social, scientific and technological development of Ghana and Africa, and to make graduate training and research continually responsive to the changing climate of the world of work. One of the missions of the School of Graduate Studies is to mobilise appropriate human and material resources from within and outside the University to ensure maximum utilisation of available potentials.

The purpose of this study was to explore the perception of 
postgraduate students on customer services at the School of Graduate Studies, University of Cape Coast. Specifically, the study looked at the service quality based on the SERVQUAL Model by Parasuraman, Zeithaml and Berry (1988). Turban, Lee, King and Chung (2002) posit, "Customer service is a series of activities designed to enhance the level of customer satisfaction that is a feel that a product or service has met a customer's expectation" (p. 87). The University expects students to commit to certain responsibilities, such as a degree of scholastic aptitude and well-roundedness, commitment to hard work and to the university's culture. Students also expect more from their universities than relevant classes. The needs of students have extended beyond the classroom and into administrative processes of the university. They expect a high level of customer service before, during and after their enrollment and in all interactions with their institutions.

Students are ambassadors of every university and could help the University to grow positively. There is, therefore, the need for the University to be customerfocused and build a customerdriven workforce to maintain excellence. Staff should provide services in such a way that it would allow customers to access services in the most efficient, fair, cost effective and humanly satisfying and pleasurable manner (Speer, 2014). Handling students in the most efficient and effective manner in this rapidly changing time is very important in order to meet the tenets of the University's mission statement. It was on this premise that a study of this nature was conducted to explore the perception of students (particularly, post-graduate students) regarding service quality at the School of Graduate Studies, University of Cape Coast.

\section{Literature Review}

Technology is revolutionising the way people interact and get their information. With technological advancement aiding service delivery systems, customer expectations continue to rise. The University of Cape Coast aims to continuously improve its teaching, learning and support services. The University 
appreciates that the factors or elements that contribute to customer satisfaction will lead to the delivery of excellent customer service that would create a customer-focused culture at the School of Graduate Studies. A customer-focused institution means everything the institution does that points to improved customer-service and satisfaction (Home of Service, 2013). Customer service is the ability to meet customers' needs and it highly depends on customers' expectations. It could mean one or a combination of being able to treat customers satisfactorily, serving customers with a smile, improving customer perception and confidence; and making customers feel that they are special and need to be pampered. It could be said that customer service is a series of activities put together to meet the customers' expectations and satisfaction. Many customers expect providers of services to be friendly, understanding, courteous, respectful, honest and loyal. They expect service providers to appreciate and treat them with some professionalism. Nickels,
McHugh and McHugh (2008) observed that products and services in the $21^{\text {st }}$ century are designed to 'fascinate, bewitch and delight customers in exceeding their expectations and making business customer-driven.

According to McShane and Von Glinow (2006), customer expectation is a powerful driving force for change in institutions, such as university of Coast. They noted that dissatisfied customers represent a compelling force for renovation, because of the adverse consequences on organisational survival and success. One of the criteria for measuring success in a customer-oriented institution is the satisfaction of both the internal and external customers. Internal customers (students) are individuals and departments within the institution that receive services from other individuals or units. Often, the value of the internal customers is overlooked. McShane and Von Glinow (2006), emphasised that employer/employee satisfaction is associated with customer satisfaction for these reasons: job satisfaction affects a person's mood for good therefore, 
employees are likely to communicate friendliness and positive emotional mood, which customers appreciate. Managing customer relationship is a complete and challenging duty that requires leadership, focus and commitment. Patterson and Smith (2000) postulate a similar view that each customer is different, hence relationship with them need to be tailored to match their needs. Good customer handling is a concept that has helped many organisations to realize their goals of being leaders in their industries. Competition for retaining customers and thereby gaining advantage over competitors has prompted many organisations to give much attention to customer relationship (Home of Service, 2013).

Customer service is committed to providing a highquality service to all its customers in a friendly, customer-focused environment. This single-minded focus on satisfying customers is achieved by understanding who the customers are and determining their real needs in the first instance. Smith (1998) posits, "if we understand who our customers are, those we would like to be our customers, identify the various groups within our customer base and understand their needs, we will be in the position to create products and services that can satisfy the customer." He said that creating customer value is such a complex and challenging task that it requires leadership focus and commitment.

\section{Empirical Review}

Rouf, Rahman, and Uddin (2016) studied students' satisfaction and service quality of higher educational institutions in Bangladesh. Using a wellstructured questionnaire as a data collection instrument, with 160 students spanning four public universities as respondents (sample), the study found significant relationship between the five dimensions of service quality (tangibility, reliability, responsiveness, assurance, and empathy) or SERVQUAL i.e. (service quality model) and students' satisfaction. In general, the results indicated that all the five dimensions of service quality were correlated with student satisfaction. 
In a comparative study on two colleges (a state and a private college) in Royal University of Bhutan (RUB), aimed at determining factors of student satisfaction in the private and the state colleges, van Deuren and Lhaden (2017) reported that the institutions under study showed both similarities and differences between the public and private colleges. Overall student satisfaction did not differ, but the perception of the quality of factors contributing to satisfaction differed. Some factors contributed to student satisfaction in both colleges, but other factors were only relevant for the private or for the public college. For example, although differences exist between the colleges under study, the findings suggest the relevance of five factors contributing to overall student satisfaction: teacher role, learning environment, administrative staff, future prospects and location. The factor "future prospects" refer to how universities prepare students for their career after graduation."

Tuan (2012) reported that the effects of service quality and price fairness on students' satisfaction in universities in Vietnam and that of administrative service quality were significantly and positively related to students' satisfaction. This finding demonstrates that the knowledge of the functioning of a university, skills and service attitude of administrative staff play a very important role in increasing students' satisfaction. Contrary to this finding, Ahmed and Masud's (2014) research in universities in Malaysia found that administrative services were not significantly related to students' satisfaction. However, their research found that quality of academic resources, lecturer quality and quality of academic programmes had a direct and significant relationship with students' satisfaction.

\section{Theoretical Framework}

The study was guided by the SERVQUAL Model by Parasuraman, Zeithaml and Berry (1988), which sets out a theoretical framework for the measurement of service quality. The SERVQUAL scale has since become the most prevailing instrument for measuring service quality. It initially comprises 10 measurements with 97 items. Consequently, this was later 
reduced to 5 measurements with 22 items in 1991. *The five dimensions are tangibles,

**Customers are required to record their perceptions of that institution's performance on those same dimensions... In a situation where perceived performance ratings fall below expectations, quality is poor (Parasuraman et al, cited in Zakari, 2016). Zakari (2016) explains that the SERVQUAL Model gives thorough information about *reliability, responsiveness, assurance and empathy. **

i.e. the customer's benchmark performance stages, as perceived by customers, customer comments and suggestions, as well as impressions from employees with respect to customer expectations. The framework guiding the study is based on the SERVQUAL Model, which is presented in Figure 1. The framework consists of five areas: responsive, assurance, reliability, empathy

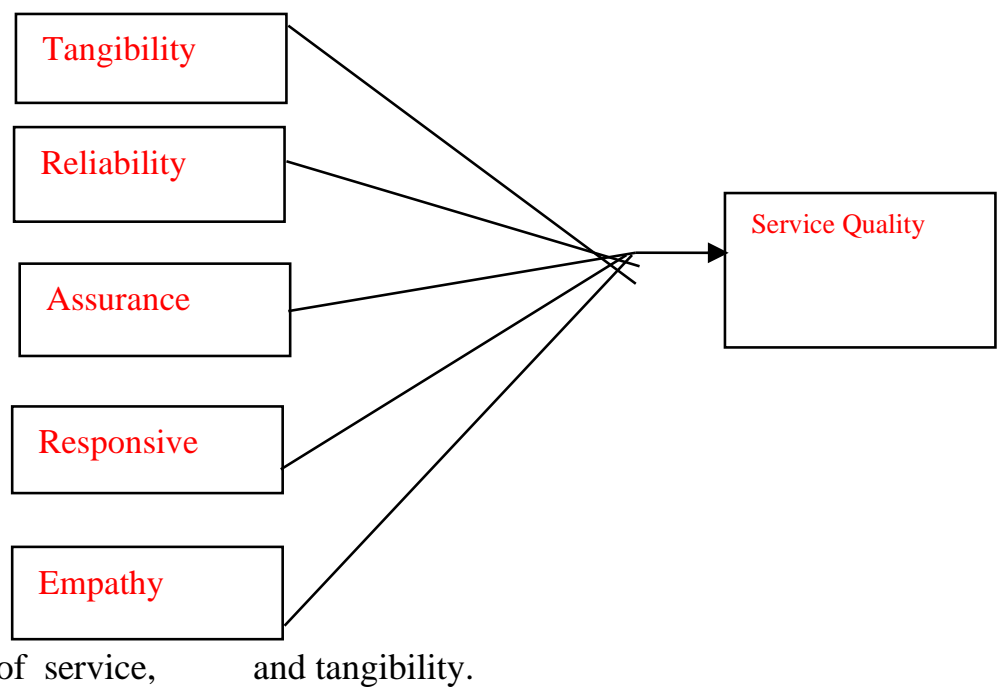

customer perceptions of service, and tangibility.

Figure 1: Strategic Customer Service Framework

Source: Author's construct (based on the SERVQUAL Model by Parasuraman et al, 1988) 
Tangibility Dimension

**Tangibles involve the physical prove of the service. According to Zeithaml, Bitner and Gremler (2006), tangibles in details normally show physical facilities of the service provider, the appearance of personnel, materials associated to the service (credit and debit sheets, cheque books etc.), decorations and business hours, the tools and equipment used to provide the service. Tangibles are usually used by firms to express image and signal quality.

\section{Reliability Dimension}

According to Zeithaml et al (2006), reliability is "the ability to perform the promised service dependably and accurately" or "delivering on the promises." Does the firm deliver the service comfortably the first time? Does the firm respect the promises? These are a portion of the inquiries that should be answered by providers of service if they are to accomplish unwavering quality. This measurement of service quality, as indicated by Parasuraman et al (1988), is the means by which the providers of service can give service to a client as promised, tried and true in dealing with clients' service issues, performs service right at the first instance, give service at guaranteed time and keep clients always informed about when service will be performed or available.

\section{Assurance Dimension}

Assurance involves the knowledge and courtesy of employees and their capacity to pass on trust and certainty. It likewise incorporates skill, obligingness, believability and security. In the view of Andaleeb and Conway (2006), assurance may not be so vital with respect to different industries where the risk is higher and the result of utilizing the service is questionable. For example, in the medical and healthcare industry, assurance is an imperative measurement that clients utilized as the principle in evaluating a health centre or a specialist for a task. The trust and ultimate confidence might be visible in an employee who connects the client to the 
organisation (Zeithaml, Bitner \& Gremler, 2006).

\section{Responsiveness Dimension}

Responsiveness concerns the ability or preparation of employees to offer service (Parasuraman, Zeithaml \& Berry, 1985). Responsiveness is concerned with managing the client's inquiries and concerns and immediately attending to concerns or providing a solution to these issues. A firm is known to be responsive when it conveys to its clients the extent to which it would go to find solutions or have their issues managed. To be effective, institutions need to look at responsiveness from the viewpoint of the client as opposed to the organization's point of view (Zeithaml et al, 2006).

\section{Empathy Dimension}

Empathy involves

minding and arrangement of individualized regard for clients by employees of the firm (Zeithaml et al, 2006). In this respect, the client feels exceptional and extraordinary. While trying to create empathy, employees of the firm should try to recall the names of their clients, their inclinations and needs and find a way to fulfill them. Small organisations through their customized services to customers are in a more superior position to accomplish empathy than large organisations.

As the framework illustrates, the interplay of the five dimensions in the model would enhance service quality in an organization. It is the view of the researcher that the model, if applied strictly in the higher education setting, could improve service to its customers. This is because most higher education institutions do not see themselves as customer driven establishments, which need to provide services such as those in the banking and other service industries. This is supported by evidence in the higher education literature e.g. Ahmed and Masud (2014), as cited in Kara, Tanui, and Kalai, (2016). Tuan (2012) postulates that administrative service quality was significantly and positively related to students' satisfaction. This finding demonstrates that the knowledge of the functioning of a university, 
skills and service attitude of administrative staff members play a particularly important role in increasing students' satisfaction. Nonetheless, the findings of Ahmed and Masud's (2014) research in universities in Malaysia found that administrative services were not significantly related to students' satisfaction. These revelations suggest that there is no clear consensus on quality services (especially administrative services) in higher education. Against this backdrop, adopting the SERVQUAL Model to guide and measure service quality helps to ensure that service quality is improved. In the researcher's view, the SERVQUAL Model is appropriate to guide the study.

Strategic Customer Service Frameworks

Many organisations and communities have used home factors and elements in building their strategic customer service frameworks, to bring about cultural change that has helped them in enhancing existing cultural practices. These organisations have been successful in creating customerfocused cultures and are leaders in their industries.

Responsibilities of Stakeholders in Improving Customer Service in UCC

Managing customer service in the University is the responsibility of the various stakeholders, and it is dependent upon understanding and commitment from both management and staff members. University management, staff members and graduate students, as stakeholders, are likely to have an impact on the success of managing customer service issues.

\section{University Management}

The University management plays a critical role in improving the quality of teaching and learning, research, community services and other functions of the University. Management should set the vision and empower other stakeholders to take responsibility for achieving it. The ViceChancellor sets the academic tone of the institution for students, teaching staff, non-teaching staff, parents and community members 
by providing effective leadership. Adopting a distributive style, involving other internal and external stakeholders in the management of the university, could enhance the efficiency and effectiveness of recruitment of high-performing intelligent employees to foster customerfocused culture. Management should be enthusiastic and articulate constant support for customer service enhancement throughout all levels of the institution. Staff members of the University of Cape Coast must be made to understand that customer service forms an integral part of their job and they should aim at satisfying each other as well as the students so that each and every one would help the University gain its worldwide acclaim. Initiatives for improving quality should not be measured on a short-term basis but should be continuous.

Teaching and Non-Teaching Staff The lecturer's role is pivotal in the improvement of quality of teaching and learning in the universities. The lecturer is a pacesetter who sets plans aimed at ensuring students' effective learning by devising learning experiences to arouse students' interest and inspire them to work diligently so as to become creative problem solvers. All over the world, the teacher is recognised as a major factor in implementing educational reform efforts aimed at improving the quality of education. It is not a matter of just providing the students' needs, but also going the extra mile to meet their expectations in order to establish excellent customer relationship with them. This requires courtesy, a sense of caring, willingness to help and the ability to solve problems in order to build values that will identify those factors that boost relationship/satisfaction. Cook (2008) posits that everyone within an organisation is a customer; and to provide service to an external customer involves a whole chain of people each satisfying the needs of their colleagues down the line. Therefore, treating staff or people with respect is necessary if the external customer is to receive excellent service. University staff should seek to design and refine business practices within the 
University's mission to provide customers with what they need in the manner they prefer.

\section{Students (Customers)}

Students are customers in the education industry striving to get the best education. The essence of the establishment of any institution of higher learning is to ensure the sound development of students academically, morally, socially, politically and spiritually. One learning outcome is the reality of students being the driving force in demanding changes in how their education needs are served. Customer service is performed in most of our educational institutions today and there are even departments dedicated to providing student services. However, real customer service must involve more than a department or a handful of individuals. Providing a true service-centred environment is everyone's job, that emphasis must start at the top and the inspiration for delivering should be more than lip service. Some would argue that higher education has focused less on the process of good customer service and more on the final product of producing educated graduates. If students fulfill the course requirements set before them, the institution awards them a diploma/degree in recognition of their accomplishment. But universities have not been as concerned about whether students felt satisfied while completing their degree requirements. They tend to emphasise, instead, that students need to work hard while at school to complete their degrees. The advantages of this approach include increased customer satisfaction and loyalty. Taking care of students should lead to increased retention, which is an increasingly important revenue source for higher education institutions. The bottom line is that institutions of higher education need students to survive and thrive.

\section{Methodology}

The study employed the descriptive survey design. This descriptive survey is designed to describe the existing situation, which is normally sought to examine the answers to who, what, when, where and how 
questions (Creswell, 2014). In this study, the cross-sectional survey under the descriptive survey design was employed. That is, the researcher collected one data for the research. The advantage of the survey design is that it allows the researcher to describe the opinions and beliefs as it is. It also allows for fast collection of data for analysis. The researcher applied the survey technique by distributing questionnaires to gain feedback from respondents and to gain an understanding of what is perceived as customer service at the School of Graduate Studies. According to Creswell (2014), a survey technique can gather data or information from people by using a questionnaire. Therefore, this survey uses a questionnaire administered by the researcher to gather data from the respondents.

The study population is the group of people who have the information that the researcher is looking for and from which conclusions could be drawn (Malhotra, \& Birks, 2007). In this case, the study population consisted of 4,269 postgraduate students (customers) from the five Colleges in the University of Cape
Coast, namely: College of Humanities and Legal Studies, College of Education Studies, College of Agriculture and Natural Resources, College of Distance Education and College of Health and Allied Sciences. From the total population, a minimum sample of 366 respondents were deemed appropriate. This was calculated, using the Sloven's formula: $\mathbf{n}=$ $\frac{N}{1+N(e) 2}$, where $\mathrm{n}=$ sample size, $\mathrm{N}$ $=$ accessible population and $\mathrm{e}=$ level of significance at 0.05 . However, the study sampled 410 respondents to ensure adequate representation. The study employed the probability sampling technique, specifically, stratified sampling, to group the respondents into their respective Colleges. The proportional stratification was to ensure adequate representation of students in each stratum i.e. college. In calculating the sample for the strata, the sample for each stratum was divided by the total population and multiplied by the sample size. A sampling frame was then developed out of which the simple random sampling technique was used to select the 
required number of respondents for the study. The table of random numbers was used to select the respondents for the study. The main instrument employed for the data collection was a structured questionnaire.

The questionnaire was designed to provide specific responses aimed at addressing the research objective. The questionnaire was developed from the literature review. It was influenced by the SERVQUAL Model by Parasuraman et al (1988) to measure the quality of service at the School of Graduate Studies, UCC. Respondents were given a questionnaire with an explanation before filling in. A 4point Likert scale was used in measuring the variables of interest that has to do with respondents' perception of customer service delivery at the School of Graduate Studies. There are some reasons behind the selection of this method. First, it allows a large quantum of information to be solicited at a relatively low cost. Second, more accurate and precise responses are obtained, because interviewer's bias can be avoided. Fifteen questions on quality service delivery were administered to the respondents on which the analysis was based. It has four items with a Likert scale from one to four. Respondents were expected to tick the option that best reflected their opinion, starting from $1=$ least agree to $4=$ highest agree.

In order to reduce the chances of getting the wrong answer, attention was given to the reliability and validity of the instrument used. Some steps were taken to ensure the validity and reliability of the study. To ensure the validity of the instrument, the draft questionnaire was given to both lecturers and administrators who are professionals and experts in the area to check how well the items were developed and whether the items were relevant in answering the research questions. The instrument (questionnaire) was subjected to further reviews by experts in higher education, especially on quality assurance. Their feedback and suggestions were incorporated in the final instruments designed for the study. This was done to ensure that the validity of the instrument was checked. To further check the 
reliability of the instrument, data were obtained from the reliable sources that means that a respondent must be a postgraduate student (customer) of the School of Graduate Studies of University of Cape Coast. The questionnaire was also pre-tested at University of Education, Winneba, Graduate Studies to ensure it measured what it was supposed to. Results from the pre-test showed Cronbach's Alpha of 0.82 in line with Pallant's (2007) suggestions.

To ensure strict compliance with ethical standards of research, written permission sought from the University, which was duly granted before data were collected. The researcher introduced a clause in the introductory paragraph of the instrument assuring respondents of anonymity and confidentiality. In addition, the time required for filling in the questionnaire was mutually agreed between the respondents and the researcher. A total of 400 questionnaires were completed and, after carefully scrutinising them, 391 questionnaires were used in the data processing and analysis. This gave a response rate of $97.6 \%$. The data gathered were analysed, using IBM SPSS (v.23). Before the main analyses were run, the data were cleaned to make sure it was the true reflection of what was on the questionnaires. Outliers were identified and corrected, by running some descriptive analysis, such as frequency, percentage, mean, standard deviation, minimum and maximum.

\section{Results and Discussion}

This section deals with the presentation and discussion of the results that were gathered from the data collected. It begins with a discussion on the background information of respondents in relation to the research questions as well as the literature review.

\section{Background information of respondents}

In the study, respondents' background characteristics were described in terms of sex and age range. The instrument designed for the collection of data for the study was questionnaire. Respondents were to indicate their background information for the purposes of classification and comparison. Background 
information of respondents was grouped, and responses were analyzed using frequencies and percentages. The results, as captured, indicated that there were more male respondents than female with males accounting for 201 (51.5\%), and females representing $190(48.5 \%)$ of the total respondents. This indicates that there are more male than female postgraduate students at the University of Cape Coast. About 175 (44.6\%) of the respondents indicated that their ages fall within the age range between 26-35 years. This was followed by 142 (36.3\%) whose ages range between 36-45 years. About $75(19.1 \%)$ of the respondents were within the age range between $18-25$ years. The finding reveals that most of postgraduate students of the university are youthful, thus between 18-45 years.

Perception of Postgraduate Student on Customer Service Quality

The research objective was to ascertain the perceptions of postgraduate students on customer service delivery at the School of Graduate Studies, UCC. The study examined customer service quality, using 15 quantitative questions in which respondents were required to indicate the extent to which they agree with each statement by indicating the number that best portrays their perception on the Likert scale. The responses were analysed, using means and standard deviations, as summarized in Table 1.

Table 1: Description of Customer Service Quality

\begin{tabular}{|l|c|c|c|}
\hline SERVQUAL Model (5 Dimensions) & $\begin{array}{c}\text { Mea } \\
\mathrm{n}\end{array}$ & $\begin{array}{c}\text { Std. } \\
\text { Desponsiveness }\end{array}$ & $\begin{array}{c}\text { Interpretati } \\
\text { on }\end{array}$ \\
\hline $\begin{array}{l}\text { Whenever I ask for service the staff serve } \\
\text { me readily in a good manner. }\end{array}$ & 3.56 & .74 & $\begin{array}{c}\text { Very high } \\
\text { level }\end{array}$ \\
\hline $\begin{array}{l}\text { When I need service, the staff give me } \\
\text { prompt service }\end{array}$ & 3.52 & .64 & $\begin{array}{c}\text { Very high } \\
\text { level }\end{array}$ \\
\hline $\begin{array}{l}\text { Always the staffs are willing to solve } \\
\text { students (customer) problems or } \\
\text { challenges }\end{array}$ & 3.42 & .85 & $\begin{array}{c}\text { Very high } \\
\text { level }\end{array}$ \\
\hline
\end{tabular}


Betty K. Addo-Nkrumah: Perception of Postgraduate Students on Customer Service at the School of Graduate Studies, University of Cape Coast

\begin{tabular}{|c|c|c|c|}
\hline Sub-total & 3.5 & & Very high \\
\hline \multicolumn{4}{|l|}{ Assurance } \\
\hline $\begin{array}{l}\text { UCC staff make students (customers) feel } \\
\text { safe in their enquiries or seeking } \\
\text { assistance }\end{array}$ & 3.05 & 1.11 & High level \\
\hline $\begin{array}{l}\text { Every time staff of UCC are consistently } \\
\text { courteous with me }\end{array}$ & 2.79 & 1.31 & High level \\
\hline $\begin{array}{l}\text { Most often UCC staff have the } \\
\text { knowledge to answer my questions. }\end{array}$ & 2.72 & 1.28 & High level \\
\hline Sub-total & 2.85 & & High level \\
\hline \multicolumn{4}{|l|}{ Reliability } \\
\hline $\begin{array}{l}\text { Postgraduate students feel secure in } \\
\text { seeking assistance or making enquiries } \\
\text { from the UCC }\end{array}$ & 2.94 & 1.25 & High level \\
\hline $\begin{array}{l}\text { When UCC promises to do something by } \\
\text { a certain time, they do it. }\end{array}$ & 2.66 & 1.21 & High level \\
\hline UCC performs services right the first time. & 2.53 & 1.31 & High level \\
\hline Sub-total & 2.71 & & High level \\
\hline \multicolumn{4}{|l|}{ Empathy } \\
\hline $\begin{array}{l}\text { Whenever I request for service, UCC staff } \\
\text { give me full and individual attention. }\end{array}$ & 2.99 & 1.26 & High level \\
\hline $\begin{array}{l}\text { Staff of UCC handle my concerns or } \\
\text { enquiries in a caring manner. }\end{array}$ & 2.84 & 1.09 & High level \\
\hline $\begin{array}{l}\text { Staff of UCC understand my specific } \\
\text { needs with a specific attention }\end{array}$ & 2.24 & 1.19 & Low level \\
\hline Sub-total & 2.69 & & High level \\
\hline \multicolumn{4}{|l|}{ Tangibility } \\
\hline $\begin{array}{l}\text { Staff of UCC dress professionally and are } \\
\text { neat in appearance. }\end{array}$ & 2.96 & 1.18 & High level \\
\hline $\begin{array}{l}\text { University of Cape Coast has modern- } \\
\text { looking equipment (computers, fast ICT } \\
\text { facilities, Computer labs etc.) }\end{array}$ & 2.59 & 1.26 & High level \\
\hline $\begin{array}{l}\text { The interior and exterior of the offices are } \\
\text { visually appealing and spacious } \\
\text { (comfortability conditions, waiting queue } \\
\text { chairs, notice board). }\end{array}$ & 1.87 & 1.02 & Low level \\
\hline Sub-total & 2.47 & & Low level \\
\hline Overall total & 2.85 & & High level \\
\hline
\end{tabular}


Key: Mean range and interpretation on the level of service quality 3.26 - 4.00 - Very high level; 2.51 - 3.25 - High level; 1.76 - 2.50 - Low level; 1.00 - 1.75 - Very low level

It is evident from Table 1 that with respect to the responsiveness dimension of service quality, the results showed that respondents expressed very high levels of agreement on the question, that whenever they ask for service in the University the staff serve them readily in a good manner $($ mean $=$ 3.56 , std $=0.74)$. The results further showed that there were very high levels of agreement on the part of respondents relative to whether when they need services from the university, staff give them prompt service (mean = 3.52, std $=0.64)$. Most respondents opined very high levels of agreement in responding to the issue that always School of Graduate Studies staff members are willing to solve problems/challenges confronting them $($ mean $=3.42$, std $=0.85$ ). These findings suggest that staff at the School of Graduate Studies are responsive to students' needs and as much as possible try to solve their problems. The findings also suggest that the School of
Graduate Studies of the University of Cape Coast, have trained the staff members to respond appropriately to students' problems. The findings further suggest that staff at the School of Graduate Studies possibly have the willingness to solve students' problems and complaints as and when they come. This might have accounted for majority of the students agreeing to the statements "whenever I ask for service, the staff serve me readily in a good manner, and when I need service, the staff give me prompt service." The findings also support the views of Brady and Cronin (2001). Brady and Cronin argue that interaction quality deals with the experience that customers have with employees who provide the services, and it is one of the factors that influence customer satisfaction. The findings of Brady and Cronin suggest that customers (and in this study students) would only agree that there is quality service being provided only when they are satisfied with the services provided to them. This further 
supports the finding of Tuan (2012). Tuan's research in universities in Vietnam found that administrative service quality was significantly and positively related to students' satisfaction. This finding demonstrates that the knowledge of the functioning of a university, skills and service attitude of administrative staff play a very important role in increasing students' satisfaction.

The results on assurance dimension revealed that most respondents affirmed highly that UCC staff make students (customers) feel safe when postgraduate students seek assistance or make enquiries $($ mean $=3.05$, std $=1.11)$. Most respondents highly agreed that at most times staff of UCC are consistently courteous with postgraduate students (mean = 2.79 , std $=1.31$ ). The results further showed high levels of agreement by respondents on the issue of whether most often UCC staff have the knowledge to answer questions posed by postgraduate students (mean = 2.72 , std $=1.28$ ). The findings suggest that staff members of the School of Graduate Studies have the knowledge, skills and courtesy of the institution (UCC) to provide good services to its students. The results further suggest that the institution has imbedded in its staff ethical standards, which makes them able to relate well with students (especially post graduate students who are mostly seen to be mature in nature). The maturity level of post graduate students requires that staff who interact with them are equipped with the courtesies, have the knowledge of their work and their institution in order to be able to provide the needed assistance, which would make the students satisfied. Furthermore, the findings suggest that students could trust the staff at the School of Graduate Studies with serious issues because, possibly, they believe the staff members can help them resolve issues. In a study on measuring higher education service quality across some selected universities in Ghana, Asinyo (2015) reports that assurance proved the second-best performing dimension in the study with the highest score, relating to student feeling safe in their 
transactions with staff in the various institutions.

In a study conducted on Assessment of students' satisfaction of service quality in Takoradi polytechnic: The students' perspective, Anwowie, et al (2015) reported that Polytechnic employees are expected to be consistently courteous with students and 84 percent of the respondents reinforced this point. Similarly, the study reported that majority of the respondents $(60$ percent $)$ agreed that Takoradi Polytechnic designs academic curriculum that is relevant to the demands and trends of the current job market. Also, 43 percent of the respondents agreed that Takoradi Polytechnic employees consistently show courtesy to students, while $22 \%$ disagreed. The high positive rating from the students might have suggested that the Takoradi Polytechnic was doing something regarding the assurance of students. The findings of Anwowie, et al (2015) corroborate this and other studies, that most of the students are satisfied with services at the assurance dimension. Thus, the staff of the School of Graduate Studies may have positioned themselves well that students can trust them with their issues as well as also exhibit high level of courtesies to students.

On the reliability dimension of service quality, the respondents highly agreed that postgraduate students feel secure in seeking assistance or making enquiries from the School of Graduate Studies $($ mean $=2.94$, std $=1.25)$. The respondents further acknowledged highly that when the School of Graduate Studies promises to do something by a certain time, keep to it (mean = 2.66, std = 1.21). Again, the respondents highly agreed that the School of Graduate Studies performs services right the first time $($ mean $=2.53$, std $=1.31$ ). The possible reason for these findings is that the students feel assured, because staff members have been equipped with the knowledge and skills to assist studies. It possibly also means that the respondents feel their issues or problems discussed with staff would be kept confidential. Regarding the issue of things being done on time, it could be 
perceived that students do not think that problems should only be solved thus, for planning purposes, they should be told when their problems can be solved. It means that for students to be satisfied with services, timelines in the provision of services is highly paramount. The findings further reveal that problems or services that have deadlines, if not delivered on time, makes it difficult for students to be satisfied. For example, students who will graduate have a certain period within which to submit their final work. If the negligence of a staff member causes student's work to delay, although the student may graduate at the next graduation ceremony available, s/he would not be pleased because s/he did not graduate at the stipulated time. The findings support that of Anwowie et al (2015), that students expect staff members in a polytechnic to tell them (students) exactly when a service will be performed. The students expect that polytechnic staff member will always respond to their requests and give prompt services. On this account, it is not only imperative that services are provided to the students, but quality service must be provided considering the time as an important factor.

On the face value, it may be seen that the School of Graduate Studies may be providing services to its students, yet, due to the bureaucratic nature of the University structure, it may be interesting to know whether staff members are able to meet timelines in the provision of services to students. The results on empathy dimension of service quality reveal that most respondents highly agreed that whenever they request for service, the university staff give them full and individual attention (mean = 2.99 , std $=1.26$ ). The results revealed that most respondents expressed high levels of agreement that staff of the University handle their concerns or enquiries in a caring manner (mean $=2.84$, std $=1.09)$. Most respondents expressed low levels of agreement on the issue that staff members of the Graduate School understand postgraduate specific needs with specific attention (mean $=2.24$, std $=1.19)$. The findings suggest that whenever 
students visit the School of Graduate Studies for services, the staff readily give the students the needed attention. This suggests that structures have been put in place for staff members to solve students' problems. The findings further suggest that staff members have been cautioned or admonished to give attention to students whenever they visited the offices for services. So, it is not surprising that students gave a low rating to the issue that staff members understand postgraduate specific needs with a specific attention. This probably may have been due to the high number of postgraduate students and the limited number of staff members at the School of Graduate Studies. The findings also suggest the School of Graduate Studies gives the needed support services to the students, as a result, leading to most students rushing there for redress instead of their affiliated Colleges. This is imperative that the first point of call for every student is his or her Department. It is only when the Department cannot handle the issue that it would be referred to the School of Graduate Studies. Against this backdrop, the high number of students that visit the School of Graduate Studies, it may be highly difficult for the staff members to know and address the concerns of every postgraduate student on time. This is further occasioned by the need to pay listening attention, adapt and be flexible in delivering what individual customers need (Zeithaml \& Bitner, 2003). These findings agree with previous studies (for example, Hensley \& Sulek, 2007; Asinyo, 2015; Anwowie et al, 2015). The findings suggest that customers become dissatisfied with a service if they should wait for a long time to be served. Many service organisations worry about customer queues as they may elicit negative perceptions on the quality of customer service. Insight from the previous studies further reports that respondents disagreed with the statement that the institution provides more individual attention. Thus, although the students acknowledge and see the need for individual attention, it was not readily available. Similarly, majority of students perceive that the staff from their institutions 
give personal attention to students. Thus, the literature suggests that due to the size of the students' population, it will be difficult to provide individual attention. This could further be hampered by the limited time and resources available to offer individual attention to students (Anwowie et al, 2015; Zeithaml \& Bitner, 2003). The position of Anwowie et al. (2015), and Zeithaml and Bitner (2003) is congruent to that of this study, that it may be difficult for the School of Graduate Studies to provide individual attention to students due to the huge number of postgraduate students.

In relation to the tangibility dimension, the study revealed that most respondents agreed highly that staff of the University dress professionally and are neat in appearance $($ mean $=2.96$, std $=$ 1.18). Furthermore, the respondents agreed highly that the University has modern-looking facilities such as computers, fast ICT facilities, computer labs and magnificent buildings etc. (mean $=2.59$, std $=1.26$ ). But the respondents expressed low levels of agreement relative to the issue that the interior and exterior of the School of Graduate Studies offices are visually appealing and spacious (comfortability conditions, waiting queue chairs, notice board $)$. $($ mean $=1.87$, std $=$ 1.02). The findings must have been the critical observation from students regarding the rooms that currently house the School Graduate Studies. A cursory look at the place indicates a lack of work space even for the staff members. This often makes students who are visiting the office to wait outside until it is their turn for services to be provided for them. As such, there are no adequate waiting area, not enough office space to keep materials as well as provide services in a comfortable manner for students at the School of Graduate Studies. This might have accounted for the low rating of tangibility dimension of the service quality by the students.

The above findings confirm Walter, Edvardsoon and Ostrom's (2010) claim, that the physical environment is crucial to students, because service delivery occurs in the physical environment where the design, production and 
delivery of the services are of value to customers. The interior and exterior of the physical environment can create positive or negative experiences to customer. Physical environment quality includes the physical and social setting in which the institution operates, such as buildings, cleanliness and availability of customer's personal space. The study, however, disagreed with the findings of Anwowie et al (2015) in a study conducted on assessment of students' satisfaction of service quality in Takoradi Polytechnic. It was reported that majority of the students (94 percent) agreed that polytechnics must have state-ofthe-art equipment, to aid staff members to provide efficient service to students. There was also high positive response from the study regarding the expectations of the appearance of physical facilities in a polytechnic. The study revealed that majority of the respondents agreed that there were user friendly physical facilities.

\section{Conclusion}

The study has shown that customer service quality at the
School of Graduate Studies, University of Cape Coast, occurs at different dimension levels. The findings suggested that, in terms of ranking of the dimensions, the School of Graduate Studies was doing quite well in the area of responsive and assurance. Similarly, there is high level of progress also in the area of reliability and empathy dimensions of quality. The findings suggest in totality that the School of Graduate Studies may be offering quality services to postgraduate students. However, a careful look at the five dimensions suggests that the School may be lacking in some, especially on tangibility dimension. The findings further suggest that measuring empathy, for example, is one of the difficult dimensions, since it is not something that can be touched. As such, depending on circumstances and time, different students may experience different phases in service quality from the staff members. For example, during peak periods (such as graduations), the staff members may not have individual attention for students, as compared to a situation where there were no 
official University activites to be attended by the staff members of the School. The findings, thus, document that responsiveness to customer service quality at the School of Graduate Studies of the University of Cape Coast is the most dominant dimension. The least customer service quality dimension is tangibility. It could further be concluded that good customer care is a shared concern, which requires the combined efforts of all the relevant stakeholders. The students, staff and other stakeholders would have specific roles to play to promote good customer care.

Based on the findings of the study, there is the need for the Directorate of Academic Planning and Quality Assurance to collaborate with the School of Graduate Studies, Colleges and the Directorate of Human Resource, to conduct regular customer service surveys, analyse data and give feedback to staff members to improve on service delivery quality and to develop a customer service culture with the best service skills. Management of the University of Cape Coast should spell out the roles of
School of Graduate Studies in the area of graduate education. This would resolve ambiguities as to which office is responsible to solve graduate students' problems i.e. whether the Department or the School of Graduate Studies. 


\section{References}

Ahmed, S. \& Masud, M. M. (2014). Measuring service quality of a higher educational institute towards student satisfaction.

American Journal of Educational Research, 2(7), 447- 455.

Andaleeb, S., \& Conway, C. (2006).

Customer satisfaction in the restaurant industry: An examination of the transaction specific model. Journal of Services Marketing, 1, 3-11.

Anwowie, S., Amoako, J., \& Abrefa, A. A. (2015). Assessment of students' satisfaction of service quality in Takoradi Polytechnic: The students' perspective. Journal of EducationPractice.

Asinyo, I. K. E. (2015). Measuring higher education service quality (A study across some selected universities in Ghana). Unpublished MPhil Thesis, University of Ghana

Brady, M. K., \& Cronin, J. J. (2001). Some new thoughts on conceptualizing perceived service quality: hierarchical approach. Journal of Marketing, 65, 34 $-49$
Cook, S. (2008). Customer care excellence: How to create an effective customer focus London: Kogan Page.

Creswell, J. W. (2014). Research design: Qualitative, quantitative, and mixed methods approaches (4th ed.). Thousand Oaks, CA: Sage Publications.

Hensley, R. L., \& Sulek, J. (2007). Customer satisfaction with waits in multi-stage services. Managing Services Quality, 17(2), $152-173$.

Home of Service (2013). Excellent customer service: A dozen best practices. Retrieved from http://cnr.nscu.edu.rrs/pdfCS Handout\%20Dozon\%Practic es.

Kara, A. M., Tanui, E. Kalai, M. J. (2016). Educational service quality and students'satisfaction in public uiniversities in Kenya. International Journal of Education and Social Science (online). Retrieved from www.ijessnet.com

Malhotra, N. K., \& Birks, D. F. (2007). Marketing research an applied approach. Essex: Pearson Education Limited. 
McShane, S. L., \& Von Glinow, M. (2006) Organizational behaviour. Emerging realities for the workplace revolution (4th ed.). Boston: McGraw Hill Companies Inc.

Nickels, W. G., McHugh, J. M., \& McHugh, S. M. (2008). Understanding business (8th ed.). Boston: McGraw-Hill Irwin.

Pedro, E. D. M, Leitao, J. \& Alves, H. (2016). Does the quality of academic life matter for students' performance, loyalty and university recommendation? Retrieved from https://www.researchgate.ne t/publication/266734145

Pallant, J. (2007). SPSS survival manual: A step by step guide to data analysis using SPSS version 15. New York, NY: McGraw-Hill.

Parasuraman, A., Zeithaml, V. A., \& Malhotra, A. (2005). E-S-QUAL: A multiple-item scale for assessing electronic service quality. Journal of Service Research, 7(10), 121.

Parasuraman, A., Zeithaml, V.A., \& Berry, L.L. (1985). A conceptual model of service quality and its implications for future research. Journal of Marketing, 49, 41-50.
Patterson, P. G., \& Smith, T. (2000). Modeling relationship strength across service types in a Eastern culture. International Journal of Service Industry Management, 12(2), 90-113.

Rouf, A. Rahman, M., \& Uddin, M. (2016). Students' satisfaction and service quality of HEIs. International Journal of Academic Research in Business and Social Sciences, 6(9),376-390.

Smith, I. A. (1998). Meeting customer needs ( $\left.2^{\text {nd }} e d.\right)$. Oxford: ButterworthHeinemann.

Speer, J. (2014). A definition to guide customer service today. Retrieved from http:/bizwatchonline.com

Tuan, N. (2012). Effects of Service Quality and Price Fairness on Student Satisfaction. International Journal of Business and Social Science, 3(19), 132150.

Tutu-Boahene, B., Akwensivie D. M. (2014). Service experience perspectives in Ghanaian private universities (online). British Journal of Marketing Studies, 2, (3), 113 
Turban, E., Lee, J., King, D., \& Chung, H. (2002). Electronic commerce: A managerial perspective. Upper Saddle River, NJ: Prentice-Hall.

van Deuren, R. Lhaden, K. (2017). Student satisfaction in higher education: a comparativestudy of $a$ private and a public college. Retrieved from: https://www.researchgate.ne t/publication/322735609

Walter, V., Edvardsoon, B., \& Ostrom, A. (2010). Drivers of customer service experiences: A study in the Restaurant industry. Managing Service Quality 20(3), 236 - 258.

Wilson, A., Zeithaml, V., Binter, M., \& Gremler, D. (2008). Service marketing: Integrating customer focus across the firm. London: McGraw-Hill.

Zakari, B. (2016). Students perception of service quality in higher educational institutions in Ghana and its effects on their loyalty. Unpublished MPhil thesis, University of Cape Coast.

Zeithaml, V. A., Bitner, M. J., \& Gremler, D. D. (2006). Services marketing: Integrating customer focus across the firm (4th ed.).
New York, USA: McGrawHill.

Zeithaml, V.A \& Bitner M.J. (2003). Services Marketing: Integrating customer focus across the firm (3rd ed.). New York: McGraw-Hill. 